\title{
Efecto de la salinidad sobre el crecimiento vegetativo de plantas de mora de Castilla (Rubus glaucus Benth.) micorrizadas y sin micorrizar
}

\author{
Salinity effect on the vegetative growth of Andean blackberry \\ plants (Rubus glaucus Benth.) inoculated and non-inoculated \\ with mycorrhizal fungi
}
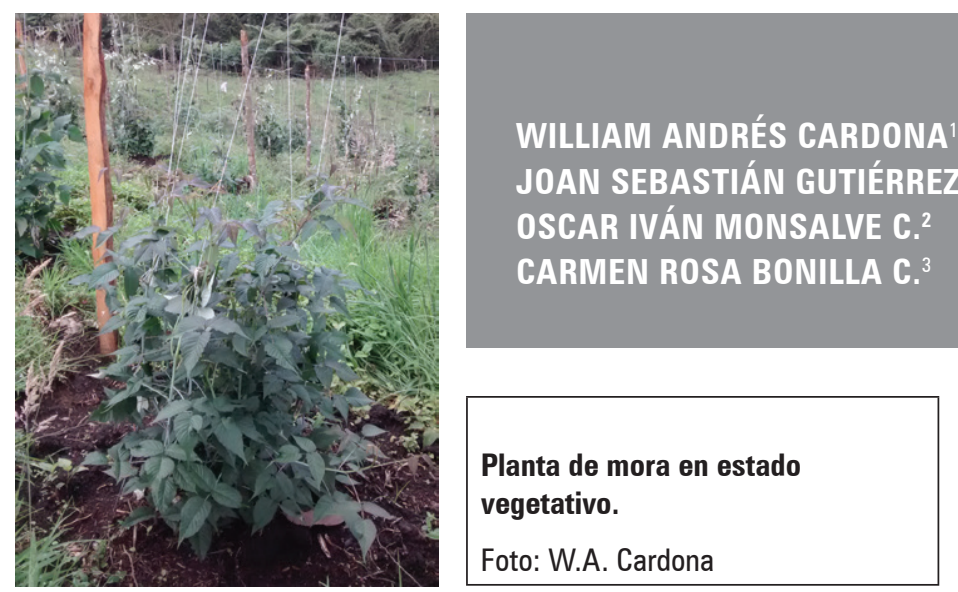

\section{RESUMEN}

La mora en Colombia generalmente se siembra en suelos sin limitantes de salinidad, pero una fertilización basada en fuentes de síntesis química sin tener en cuenta sus requerimientos nutricionales o usar gallinaza sin compostar, podría ocasionar un efecto salino a largo plazo. En esta investigación se estimó el efecto de diferentes concentraciones de solución salina $(0,40,80$ y $120 \mathrm{mM} \mathrm{NaCl})$ sobre el crecimiento vegetativo y absorción de nutrientes de plantas de mora de Castilla (Rubus glaucus Benth.) micorrizadas con Glomus proliferum Dalpé \& Declerck cepa GB02 y sin micorrizar. Se estableció un diseño completamente al azar en arreglo factorial $(4 \times 2)$. Se evaluó crecimiento radical, acumulación de materia fresca y seca, concentración y absorción de nutrientes en hoja, tallo y raíz. Se encontró que la inoculación con micorrizas incrementó el crecimiento de las plantas bajo condiciones de estrés salino $(40$ y $80 \mathrm{mM})$, debido a un posible aumento de la adquisición de nutrientes minerales con una baja movilidad y a la toma reducida del $\mathrm{Na}$. Con una concentración salina de $120 \mathrm{mM}$ se disminuyó la absorción de Ca y se aumentó la de $\mathrm{Na}$, lo que conllevó un menor consumo de agua. Igualmente, la planta disminuyó su capacidad para producir suficientes fotoasimilados que promovieran su desarrollo y el del hongo formador de micorriza, por lo que su crecimiento y producción de biomasa disminuyó notablemente. La asociación con el hongo permitió una mayor selectividad de la planta por el ión potasio, que por el sodio.

1 Corporación Colombiana de Investigación Agropecuaria (Corpoica), C.I. Tibaitatá, Mosquera (Colombia). ORCID Cardona, W.A.: 0000-0001-9610-4135

2 Facultad de Ciencias Agrarias, Programa de Maestría en Ciencias Agrarias, Línea de Investigación en Suelos y Aguas, Universidad Nacional de Colombia, Bogotá (Colombia). ORCID Gutiérrez D., J.S.: 0000-0001-6052-9588; ORCID Monsalve C., O.I.: 0000-0003-2302-805X

3 Departamento de Agronomía, Facultad de Ciencias Agrarias, Universidad Nacional de Colombia, Bogotá (Colombia). ORCID Bonilla C., C.R.: 0000-0003-1026-1004

4 Autor para correspondencia.wacardona@unal.edu.co 


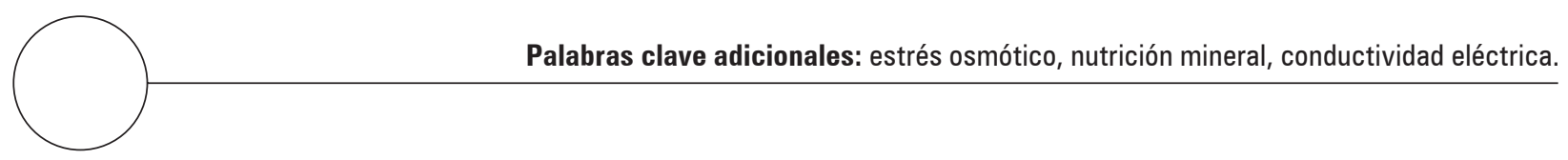

ABSTRACT

Andean blackberry is usually sown in soils without salinity limitations, but the use of fertilizers based on sources of chemical synthesis that do not take into account nutritional requirement or the use of chicken manure without composting can cause a long-term salinity effects. In this research, the effect of different concentrations of a saline solution $(0,40,80$ and $120 \mathrm{mM} \mathrm{NaCl})$ on the vegetative growth and nutrient uptake of Andean blackberry plants (Rubus glaucus Benth.), inoculated and non-inoculated with mycorrhizal fungi (Glomus proliferum Dalpe \& Declerck strain GB02), was evaluated. A completely randomized design with a factorial arrangement $(4 \times 2)$ was established. Radical growth, accumulation of fresh and dry matter, concentration and absorption of nutrients in the leaves, stems and roots were evaluated. It was found that inoculation with mycorrhizal fungi increased plant growth under saline stress (40 and $80 \mathrm{mM}$ ) because of a possible increase in the acquisition of mineral nutrients with low mobility and a reduced intake of $\mathrm{Na}$. At $120 \mathrm{mM}$, the Ca uptake decreased and $\mathrm{Na}$ increased, resulting in a lower water consumption. The plants diminished the capacity to produce enough photo-assimilates to promote development of the plants and the mycorrhizal fungi; therefore, growth and biomass production decreased. The association with the fungus allowed for a greater selectivity by the plants for the potassium ion than the sodium ion.

Additional key words: osmotic stress, mineral nutrition, electric conductivity.

Fecha de recepción: 16-05-2017 Aprobado para publicación: 30-09-2017

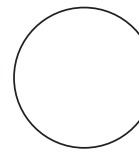

\section{INTRODUCCIÓN}

La degradación química del suelo por procesos como la salinización, está afectando y restringiendo áreas dedicadas tradicionalmente a la agricultura y por consiguiente la posibilidad de obtener rendimientos elevados y cultivar diversas especies vegetales (Goykovic y Saavedra, 2007).

Los problemas relacionados con la salinización están afectando diversas áreas de suelo alrededor del mundo; en Colombia, 10\% del área terrestre presenta niveles moderados a altos de salinidad (Miranda, 2011) y 600.000 ha del área agrícola cultivada está afectada por este factor (Casierra-Posada et al., 2000).

La salinización es originada por exceso de sales que presentan una solubilidad más alta que el sulfato cálcico $\left(\mathrm{CaSO}_{4}\right)$ (Ulloa et al., 2006). Munns et al. (2005) afirman que entre las sales que principalmente afectan las plantas, se encuentran las relacionadas con sulfatos y cloruros de cationes citotóxicos provenientes de metales alcalinos y alcalinotérreos como calcio, sodio y magnesio (Chinnusamy et al., 2005). La acumulación de sales en la zona radical y en tejidos de la planta causa estrés osmótico e interrumpe la homeostasis iónica celular a través de la inhibición de la toma de nutrientes esenciales y la acumulación de $\mathrm{Na}^{+}$y $\mathrm{Cl}^{-}$hasta niveles potencialmente tóxicos dentro de las células (Marschner, 2002; Rui et al., 2009; Memon et al., 2010).

Aunque el cultivo de mora en el país usualmente se siembra en suelos sin restricción por salinidad, los escasos estudios sobre requerimientos nutricionales del cultivo (Cardona, 2017) podrían generar problemas de salinidad por el uso inadecuado de fertilizantes de síntesis química o de gallinaza sin un previo proceso de compostaje, por tanto, es importante evaluar la tolerancia de la planta frente a una eventual condición salina en el suelo, originada por estas problemáticas.

Para reducir los efectos causados por la salinización sobre la productividad de los cultivos, es necesario emplear herramientas y mecanismos tolerantes a este factor. Según Smith y Read (2008) los hongos formadores de micorrizas arbusculares (HFMA) están en la mayoría de los suelos y se encuentran asociados a 
las plantas mediante una relación simbiótica, la cual permite mejorar la absorción de agua y nutrientes, e igualmente permite que las plantas tengan una mayor tolerancia a distintos tipos de estrés, tanto bióticos como abióticos. Al-Karaki (2006), Pérez y Peroza (2013) afirman que los HFMA permiten que las plantas se adapten a condiciones salinas en suelo. Los HFMA permiten un aumento en el crecimiento de las plantas y mejora sus relaciones hídricas mediante cambios en procesos como transpiración y la conductancia estomática (Rilling y Mummey, 2006).

Teniendo en cuenta las ventajas del uso de HFMA y que actualmente son pocas las investigaciones relacionadas con la simbiosis HFMA y plantas de mora cultivadas en condiciones de salinidad del suelo; esta investigación tuvo como objetivo evaluar el efecto de concentraciones variables de cloruro de sodio $(\mathrm{NaCl})$ sobre el crecimiento vegetativo inicial de plantas de mora de Castilla micorrizadas y no micorrizadas.

\section{MATERIALES Y MÉTODOS}

\section{Localización}

El experimento se llevó a cabo bajo invernadero en el Centro de Investigación Tibaitatá de la Corporación Colombiana de Investigación Agropecuaria (Corpoica), localizado a 441'43,1349" N y 74'12'18,7666" W, a una altitud de $2.600 \mathrm{~m}$, temperatura y humedad relativa promedio de $13,1^{\circ} \mathrm{C}$ y $80 \%$, respectivamente.

\section{Material vegetal}

Las plántulas de mora de Castilla con aguijón provenientes de propagación por vía sexual (cada plántula tenía entre tres a cuatro hojas), se trasplantaron en materas de $500 \mathrm{~cm}^{3}$, en sustrato compuesto por suelo y arena cuarcítica, en proporción 3:1. Antes de la aplicación de los tratamientos, las plántulas se aclimataron bajo polisombra negra (65\% de sombrío) durante un período de $15 \mathrm{~d}$. Semanalmente cada plántula recibió $100 \mathrm{~cm}^{3}$ de solución nutritiva Hoagland y Arnon.

Se estableció un diseño completamente al azar en arreglo factorial. Se evaluó el factor salinidad, con cuatro niveles, correspondientes a diferentes concentraciones de $\mathrm{NaCl}: 0,40,80$ y $120 \mathrm{mM}$. El segundo factor evaluado fue la inoculación de suelo con micorrizas, con dos niveles correspondientes a suelo inoculado con Glomus proliferum Dalpé et Declerck cepa GB02, a razón de 2 g por planta (60 a 70 esporas por gramo), y suelo sin aplicación de micorrizas. Las respectivas soluciones salinas se aplicaron dos veces por semana, usando $100 \mathrm{~cm}^{3}$ por planta. Para el nivel $0 \mathrm{mM}$ se aplicó agua destilada con la misma frecuencia y volumen.

Se establecieron tres repeticiones por tratamiento, para un total de 24 unidades experimentales (UE). En cada UE se tuvo dos plántulas, para un total de 48 individuos.

Las variables relacionadas con desarrollo radical (longitud y volumen) se midieron según metodología de Cardona et al. (2016a). Se registró contenido de clorofila, empleando el clorofilómetro Minolta SPAD 502. En cada órgano de la planta (hoja, tallo y raíz) se registró peso fresco y seco, según metodología de Bolaños et al. (2014) y Cardona et al. (2016b) y utilizando la balanza marca Ohaus modelo Scout Pro (Ohaus, México D.F.). Una vez registrado el peso seco de cada órgano, se envió cada muestra al laboratorio de química analítica de Corpoica, donde se determinó la concentración de nutrientes según los protocolos del laboratorio (NTC ISO/IEC 17025, 2005). Finalmente se determinó: absorción de nutrientes (siguiendo la metodología de Bertsch, 2005), índice vegetativo para cada órgano (según metodología de Valenzuela et al., 1993), índice de esbeltez (relación parte aérea / parte radical) y relaciones catiónicas en tejido: $\mathrm{Na}^{+} / \mathrm{Ca}^{++}$, $\mathrm{Ca}^{++} / \mathrm{K}^{+}$y K ${ }^{+} / \mathrm{Na}^{+}$.

\section{Análisis de datos}

Se realizó un Análisis de Componentes Principales (ACP) para las variables correspondientes al crecimiento de la planta; concentración y absorción de nutrientes y relaciones catiónicas en cada órgano, con el fin de reducir la dimensión de datos.

Posteriormente, se realizó un análisis de varianza multivariante (MANOVA), tomando el número de componentes que explicara más del $80 \%$ de la variabilidad de datos originales. Se realizó MANOVA para índices fisiológicos (índice vegetativo por órgano e índice de esbeltez). En caso de encontrar diferencias significativas, se aplicó test de Tukey $(P \leq 0,05)$. El análisis estadístico se realizó en el software $\mathrm{R}$, usando el paquete agricolae (de Mendiburu, 2015). 


\section{RESULTADOS Y DISCUSIÓN}

\section{Crecimiento de la planta}

La figura 1 ilustra las correlaciones entre cada una de las variables de estudio; codificadas de la siguiente manera: longitud y volumen de raíz (LR y VR, respectivamente), contenido de clorofila (SPAD), peso fresco de hoja, tallo y raíz (PFH, PFT y PFR, respectivamente) y peso seco de hoja, tallo y raíz (PSH, PST y PSR, respectivamente) y cada componente principal (CP) extraído. Con base en esta información, se puede deducir en qué componente está representada la mayor variabilidad de un parámetro en particular. En este caso, los componentes seleccionados (CP1, CP2, CP3 y CP4), representan $82,2 \%$ de la variación total de los datos originales.

Mediante MANOVA se encontró interacción significativa $(P \leq 0,0001)$ entre salinidad y micorrizas (Tab. 1) para variables relacionadas con el crecimiento de la planta (CP1 y CP3). Para las variables agrupadas en los componentes CP2 y CP4 (crecimiento radical) no se presentaron diferencias significativas; resultados que se atribuyen posiblemente al período de evaluación en vivero (Bolaños et al., 2014; Cardona et al., 2016b).

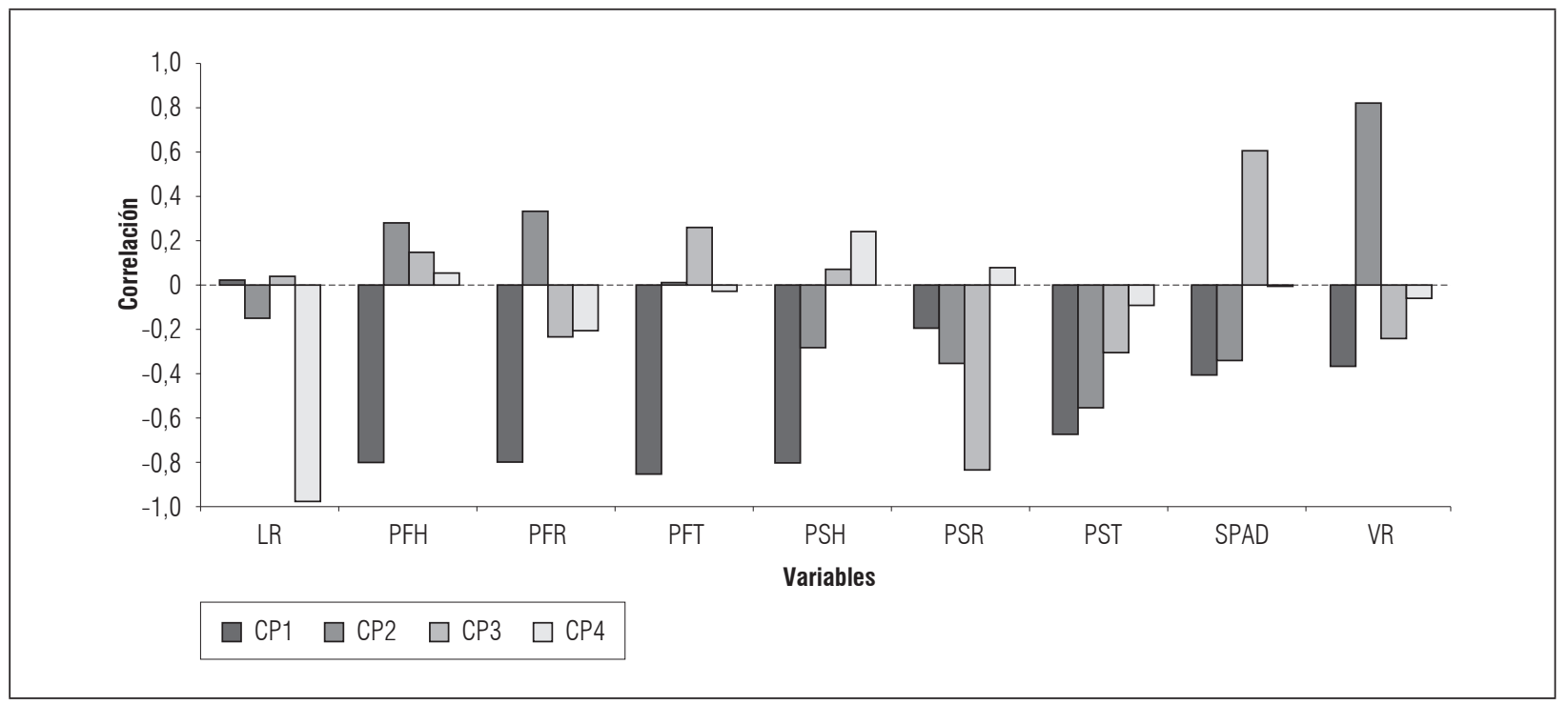

Figura 1. Correlación entre variables estudiadas y componentes extraídos a partir de variables de crecimiento de plántulas de mora (Rubus glaucus Benth.).

Tabla 1. Prueba de comparación para los componentes CP1 y CP3, correspondientes al grupo de variables del conjunto “Crecimiento de planta". Promedios con letras distintas indican diferencia significativa según la prueba de Tukey $(P \leq 0,05)$. $n=3$.

\begin{tabular}{|c|c|c|c|c|c|c|c|}
\hline CP & Tratamientos & Media & $P$ & CP & Tratamientos & Media & $P$ \\
\hline \multirow{8}{*}{ CP1 } & CM120 & 2,65 & $\mathrm{a}$ & \multirow{8}{*}{ CP3 } & SM40 & 1,18 & $\mathrm{a}$ \\
\hline & SM40 & 0,87 & $a b$ & & CMO & 0,95 & a \\
\hline & SM80 & 0,80 & $a b$ & & CM80 & 0,79 & $\mathrm{a}$ \\
\hline & CM80 & 0,28 & $a b$ & & SM80 & 0,72 & $\mathrm{a}$ \\
\hline & SMO & $-0,37$ & $a b$ & & CM40 & 0,40 & $\mathrm{a}$ \\
\hline & CMO & $-0,74$ & $a b$ & & SM0 & $-1,29$ & $\mathrm{~b}$ \\
\hline & SM120 & $-1,41$ & $\mathrm{~b}$ & & CM120 & $-1,36$ & $b$ \\
\hline & CM40 & $-2,07$ & $\mathrm{~b}$ & & SM120 & $-1,39$ & $\mathrm{~b}$ \\
\hline
\end{tabular}


Las variables asociadas al componente 1 (peso fresco de cada órgano y peso seco de la parte aérea), presentaron valores más altos con la inoculación con micorriza, bajo una concentración salina de $40 \mathrm{mM}$. Con base en esto, se podría afirmar que la mora micorrizada puede tolerar hasta una concentración de $40 \mathrm{mM}$ de $\mathrm{NaCl}$, en contraste con plántulas que recibieron la misma concentración de sales pero cuyo sustrato no fue inoculado; resultados similares a lo encontrado por Casierra y Hernández (2006) en plantas de mora que mostraron una tolerancia muy baja a la salinidad por $\mathrm{NaCl}(20 \mathrm{mM})$, la cual se manifestó mediante crecimiento limitado de la parte aérea, producción reducida de materia seca y escasa tasa de evapotranspiración. Adicionalmente se observa que a pesar de que no se presentaron diferencias estadísticamente significativas en plántulas micorrizadas y sin micorrizar sin aplicación de solución salina (CM0 y SM0, respectivamente), las micorrizas promueven mejor desarrollo de la planta (Roveda et al., 2007), representado en un valor de clorofila superior (plántulas $\mathrm{CM}=18,0$ en contraste con plántulas $S M=11,8$ ). El aumento de la salinidad causa una reducción en el contenido de clorofila (Sheng et al., 2008) debido a la supresión de enzimas específicas que son responsables de la síntesis de pigmentos fotosintéticos (Murkute et al., 2006). Una reducción en la absorción de minerales (por ejemplo, $\mathrm{Mg}$ ) necesaria para la biosíntesis de clorofila también reduce la concentración de clorofila en la hoja (El-Desouky y Atawia, 1998). Varios autores han observado un mayor contenido de clorofila en las hojas de plantas micorrizadas bajo condiciones salinas (Zuccarini, 2007; Colla et al., 2008; Sheng et al., 2008). En presencia de micorrizas, el efecto antagónico de $\mathrm{Na}^{+}$sobre la absorción de $\mathrm{Mg}^{2+}$ es contrabalanceado y suprimido (Giri et al., 2003). Las plantas inoculadas bajo estrés salino alcanzan niveles de capacidad fotosintética (estimados por el contenido de clorofila) incluso superiores a las de plantas no estresadas, mostrando que la micorrización es capaz de contrarrestar completamente el estrés (Zuccarini, 2007).

Las diferencias significativas entre plántulas cuyo sustrato fue inoculado y $\sin$ inocular y que recibieron una concentración de $120 \mathrm{mM}$ de solución salina, indican que bajo esta concentración la planta no logra producir los suficientes fotoasimilados para acumular materia seca en su parte aérea y por tanto redistribuye una parte al sostenimiento de la micorriza, presentándose menor peso seco en plántulas micorrizadas. Al respecto, Saint-Etienne et al. (2006) encontraron que la colonización de micorrizas disminuye cuando aumenta la concentración salina en suelo.

Respecto al componente 3 (contenido de clorofila y peso seco de raíz) es probable que el exceso de sales (120 mM) aumentara la capacidad vertedero del sistema radical y por consiguiente la acumulación de materia seca; adicionalmente, este efecto puede estar relacionado con la acumulación de osmolitos y evitar la pérdida de agua por gradiente de concentración, igualmente por diferencias entre los potenciales hídricos del suelo y la raíz. Este aumento en producción de fotoasimilados se ve reflejado en mayor contenido de clorofila en plántulas afectadas por exceso de sales. Por otro lado, no se observa un efecto diferencial entre plántulas micorrizadas frente a las que no recibieron el inóculo; para las demás concentraciones salinas; muy probablemente se deba al corto tiempo de evaluación en vivero. Debido a que no se encontraron diferencias significativas entre plántulas que recibieron soluciones salinas de $0-80 \mathrm{mM}$ se puede clasificar la mora como una especie tolerante a la salinidad; contrastando con lo encontrado por Casierra y Hernández (2006). Al respecto, Miranda et al. (2012) evaluando el efecto de la salinidad en plántulas de uchuva en etapa de vivero, no encontraron diferencias significativas en acumulación de materia seca entre 0 y $30 \mathrm{mM} \mathrm{NaCl}$, clasificando la uchuva como moderadamente tolerante a la salinidad.

El crecimiento vegetativo y la materia seca de los diferentes órganos de la planta, son los mejores indicadores de la tolerancia salina (Kepenek y Koyuncu, 2002). Los resultados en este estudio concuerdan con lo encontrado por Miranda et al. (2012) quienes observaron un efecto diferenciado de la masa seca en cada órgano, bajo diferentes soluciones salinas.

El menor peso fresco en tallo y hoja (Tab. 1) con la concentración más alta de $\mathrm{NaCl}$, se debió a la disminución de la expansión del área foliar como una medida de ahorro de agua (Dodd y Davies, 2004), ya que, para compensar el estrés salino, las plántulas absorben menos agua (Marschner, 2002); igualmente se pudo deber a la pérdida de lámina foliar como consecuencia del estrés. Los efectos fundamentales del cloruro de sodio en los indicadores morfofisiológicos, tienen que ver con la toxicidad de iones, que determinan las reducciones en el crecimiento y las divisiones celulares mitóticas (Casierra y Hernández, 2006; Mohamedin et al., 2006), así como también la absorción de agua y la actividad metabólica (Ghoulam et al., 2002). 


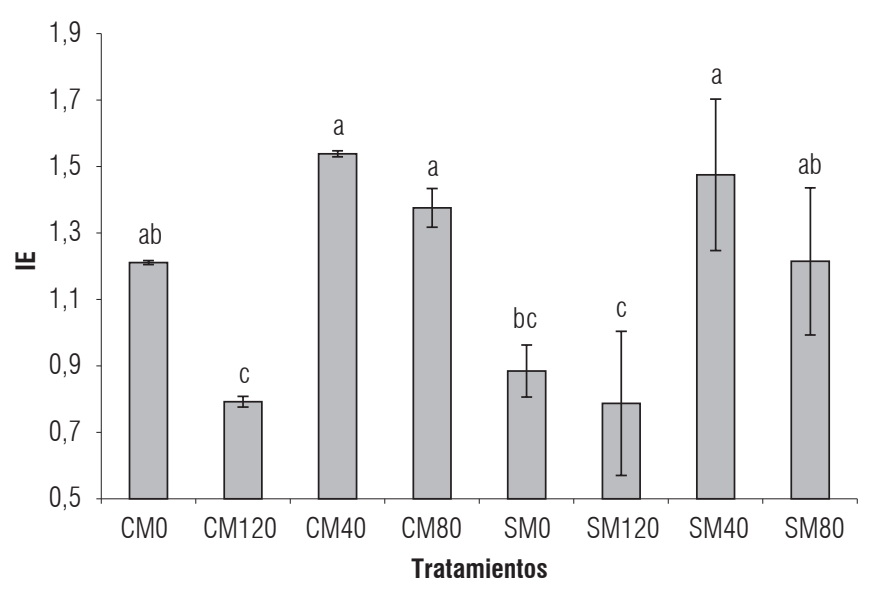

Figura 2. Índice de esbeltez (IE) para las plántulas de mora (Rubus glaucus Benth.) con y sin micorrizas (CM y SM, respectivamente) sometidas a diferentes concentraciones salinas (0, 40, 80 y $120 \mathrm{mM})$. Promedios con letras distintas indican diferencia significativa según la prueba de Tukey $(P \leq 0,05) . n=3$.

\section{Índices fisiológicos}

El índice de esbeltez que indica la relación de masa seca aérea y radical, fue afectado por diferentes soluciones salinas, encontrándose un desbalance en plántulas que recibieron solución salina de $120 \mathrm{mM}$ de $\mathrm{NaCl}$, independiente del factor micorriza, es decir, que estas plántulas presentaron una relación por debajo de la proporción recomendada (1:1). Las plántulas que más se acercaron a una proporción ideal, fueron las que no recibieron el efecto de ninguno de los factores (SM0; $\mathrm{IE}=1: 0,9)$, mostrando el comportamiento fisiológico normal (Fig. 2).

Al evaluar el índice vegetativo propuesto por Valenzuela et al. (1993), que vincula la relación NPK/CaMg entre diferentes órganos de la planta, no se encontraron diferencias significativas entre tratamientos para tallos y raíces de plántulas de mora (Fig. 3). Cabe resaltar el efecto diferencial entre plántulas con micorrizas que recibieron 40 y $80 \mathrm{mM}$ de $\mathrm{NaCl}$, frente a las que recibieron estas mismas concentraciones, pero cuyo sustrato no fue inoculado; esta respuesta indica el efecto benéfico que tienen las micorrizas en el transporte de nutrientes claves en el crecimiento, como es el caso del nitrógeno, lo que se refleja a su vez en mayor acumulación de materia seca en órganos aéreos.

\section{Relaciones catiónicas}

Las relaciones catiónicas, principalmente $\mathrm{K}^{+} / \mathrm{Na}^{+}$juegan un papel vital en la reducción del crecimiento en plántulas bajo condiciones salinas; ya que mantener una relación $\mathrm{K}^{+} / \mathrm{Na}^{+}$alta, es indicativo de tolerancia a salinidad. En la figura 4 se ilustra las medidas de correlación entre variables estudiadas y componentes extraídos.

En los tres primeros componentes, la proporción de variación total explicada es de 0,846 . Las variables asociadas a los componentes 2 y 3 no presentaron diferencias significativas.

Mediante MANOVA se encontró interacción significativa $(P \leq 0,05)$ entre salinidad y micorrizas (Tab. 2$)$ para las relaciones catiónicas.

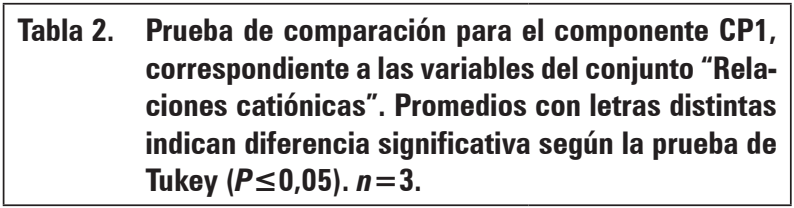

\begin{tabular}{|c|c|c|}
\hline Tratamientos & Media & $P$ \\
\hline CM120 & 2,90 & $\mathrm{a}$ \\
\hline SM120 & 2,09 & $\mathrm{ab}$ \\
\hline CM80 & 1,23 & $\mathrm{~b}$ \\
\hline SM80 & 0,01 & $\mathrm{c}$ \\
\hline CM40 & $-0,25$ & $\mathrm{c}$ \\
\hline SM40 & $-0,53$ & $\mathrm{c}$ \\
\hline CM0 & $-1,82$ & $\mathrm{~d}$ \\
\hline SM0 & $-3,61$ & $\mathrm{e}$ \\
\hline
\end{tabular}

En la tabla 2 se observa que plántulas que no recibieron soluciones salinas, ni fueron micorrizadas, 


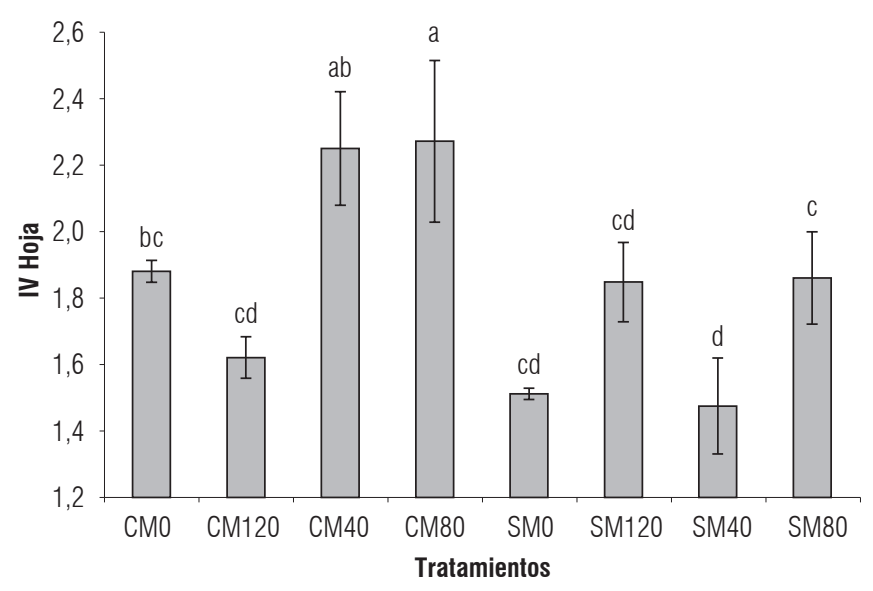

Figura 3. Índice vegetativo (IV) de hoja para las plántulas de mora (Rubus glaucus Benth.) con y sin micorrizas sometidas a diferentes concentraciones salinas. Promedios con letras distintas indican diferencia significativa según la prueba de Tukey $(P \leq 0,05) . n=3$.

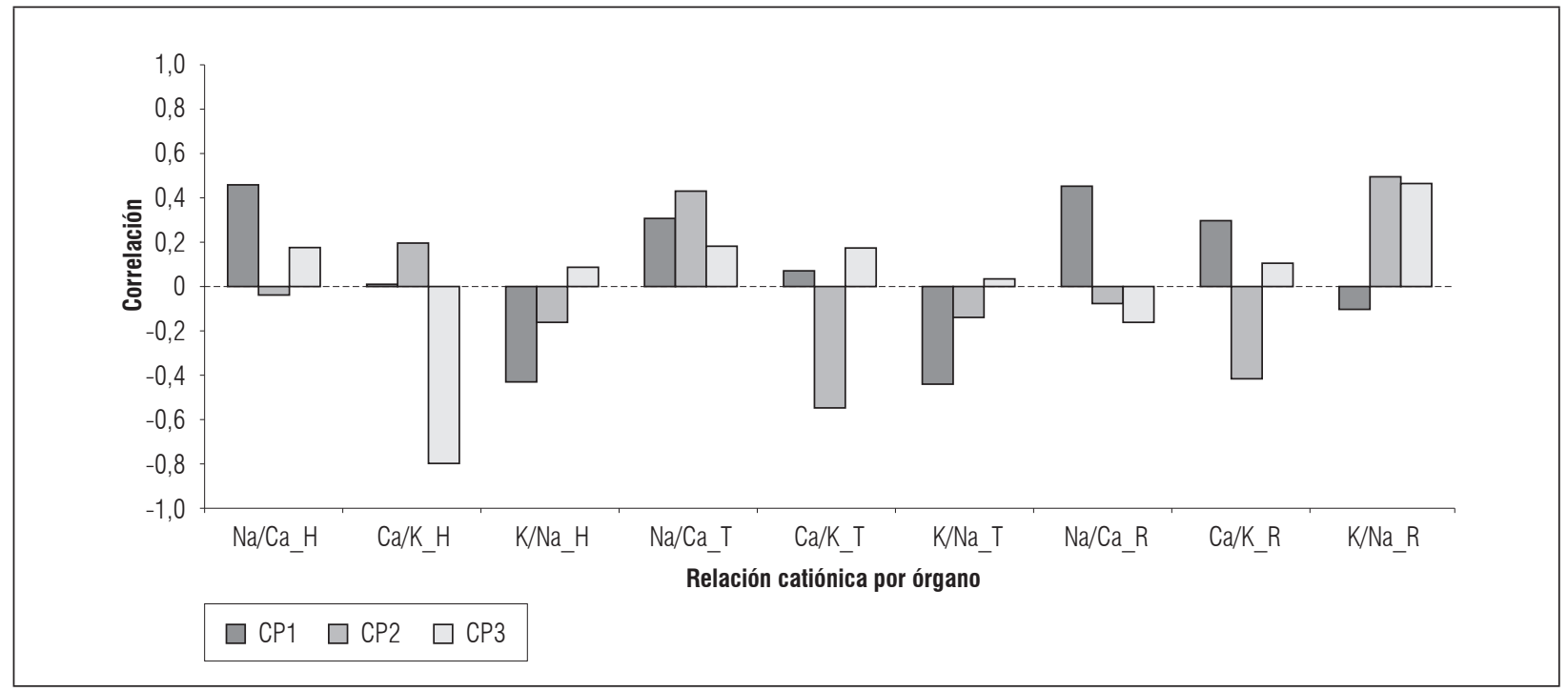

Figura 4. Correlación entre componentes extraídos y relaciones catiónicas en órganos de las plántulas. H: Hoja; T: Tallo y R: Raíz.

presentaron relaciones catiónicas $\left(\mathrm{Na}^{+} / \mathrm{Ca}^{++}{ }_{-} \mathrm{H}\right.$ y $\mathrm{Na}^{+} / \mathrm{Ca}^{++}$R) más bajas. Estas relaciones evidēncian el efecto perjudicial que tiene la aplicación de soluciones salinas sobre el sustrato, ya que el sodio (monovalente) al competir con el calcio (divalente) en solución, tiene más probabilidad por su carga, de ser asimilado por la planta. Bajo todas las soluciones salinas, plántulas que recibieron el inóculo de micorrizas, presentaron relaciones catiónicas más desbalanceadas en raíz (mayor absorción de $\mathrm{Na}$ con relación a $\mathrm{Ca}$ ). Esto podría indicar que las micorrizas ayudan a las plántulas a mejorar la preferencia por cationes monovalentes como el $\mathrm{Na}^{+}$en vez de asimilar $\mathrm{Ca}^{++}$, que funcionalmente cumple un papel fundamental en las paredes celulares de las plántulas y en el desarrollo de los aguijones en la mora. Sin embargo, cabe resaltar que la carga monovalente del sodio, a nivel iónico, tiene mayor preferencia de absorción por la planta. En contraste, se puede observar que las relaciones catiónicas $\left(\mathrm{K}^{+} / \mathrm{Na}^{+}{ }_{-} \mathrm{H}\right.$ y K $\left.{ }^{+} / \mathrm{Na}^{+}{ }_{-} \mathrm{T}\right)$ fueron significativamente más altas en las plántulas micorrizadas que recibieron diferentes concentraciones salinas (Tab. 2), 
mostrando el papel de las micorrizas en ayudar a la toma de $\mathrm{K}^{+}$con relación a la menor absorción de $\mathrm{Na}^{+}$.

Cuando la concentración de $\mathrm{Na}^{+}$en el suelo es alta, las plantas tienden a absorber más $\mathrm{Na}^{+}$, lo que resulta en una disminución de la captación de $\mathrm{K}^{+}$. Los iones $\mathrm{Na}^{+}$compiten con $\mathrm{K}^{+}$por sitios de unión esenciales para diversas funciones celulares. El potasio juega un papel clave en el metabolismo de las plantas pues activa una gama de enzimas y juega un papel importante en los movimientos estomáticos y la síntesis de proteínas. Para este último se requieren altas concentraciones de $\mathrm{K}^{+}$, ya que $\mathrm{K}^{+}$se usa en la unión de ARNt a los ribosomas (Blaha et al., 2000). Estas funciones no pueden ser reemplazadas por iones $\mathrm{Na}^{+}$(Giri et al., 2007). Una mayor proporción de $\mathrm{Na}^{+}: \mathrm{K}^{+}$generada debido a la salinidad interrumpe el equilibrio iónico en el citoplasma, lo que perturba varias vías metabólicas (Giri et al., 2007). La colonización micorrízica de una planta puede revertir el efecto de la salinidad sobre la absorción de $\mathrm{K}^{+}$y $\mathrm{Na}^{+}$; ya que puede aumentar la absorción de $\mathrm{K}^{+}$en condiciones salinas (Sharifi et al., 2007, Zuccarini y Okurowska, 2008), mientras que se evita la translocación de $\mathrm{Na}^{+}$en tejidos. La absorción de $\mathrm{K}^{+}$se incrementa en tejidos de plantas micorrizadas, incluso a un nivel de salinidad alto $\left(9,5 \mathrm{dS} \mathrm{m}^{-1}\right)$. Esto aumenta la relación $\mathrm{K}^{+}: \mathrm{Na}^{+}$en las raíces y brotes de plantas micorrizadas (Giri et al., 2007). La mayor proporción de $\mathrm{K}^{+}: \mathrm{Na}^{+}$ayuda a prevenir la interrupción de diversos procesos enzimáticos mediados por $\mathrm{K}$ y la inhibición de la síntesis de proteínas. El $\mathrm{Na}^{+}$ más bajo en plantas micorrizadas también puede explicarse por el efecto de dilución debido al aumento del crecimiento (Al-Karaki, 2006).

La interferencia de iones de la solución salina produce una deficiencia de nutrientes, lo que desencadena limitaciones adicionales (Grattan y Grieve, 1999). La inhibición en la absorción de nutrientes, el transporte y la utilización por la planta, como resultado de un alto estrés salino, contribuye también a la reducción en el crecimiento de la planta (Marschner, 2002).

\section{Absorción de nutrientes en hoja}

En la figura 5 se presenta la correlación entre variables asociadas a la absorción de nutrientes en hojas de plántulas de mora y cada componente extraído a partir de estas variables. Cuatro componentes (CP1, CP2, CP3 y CP4) representaron $82,4 \%$ de la variabilidad acumulada de los datos.
Mediante MANOVA se encontró interacción significativa $(P \leq 0.0001)$ entre salinidad y micorrizas (Tab. 3) para la absorción de nutrientes foliares.

En la figura 5 se puede observar la relación antagónica que se presenta entre dos cationes monovalentes, potasio como nutriente esencial y sodio como elemento tóxico para la planta de mora, evidenciándose que a pesar de estar en un mismo componente (CP2), presentan una relación inversamente proporcional. En Brassicaceae, Ashraf y McNeilly (2004) sugieren que mantener en el tejido una relación $\mathrm{K}^{+} / \mathrm{Na}^{+}$alta, es indicativo de tolerancia a salinidad.

Según el componente 1 (CP1), la mayor absorción de macronutrientes ( $\mathrm{N}, \mathrm{P}, \mathrm{Mg}$ y $\mathrm{S}$ ) se presentó en plántulas micorrizadas que recibieron soluciones salinas de 40 y $80 \mathrm{mM}$, en contraste con plántulas no micorrizadas que recibieron las mismas concentraciones; indicando el efecto benéfico de utilizar micorrizas para plántulas de mora que potencialmente se pudieran sembrar en suelos con problemas de salinidad; resultados que concuerdan con lo encontrado por Giri et al. (2007) y Shokri y Maadi (2009) en plantas de Acacia nilotica y Trifolium alexandrium, respectivamente. Igualmente, sin tener en cuenta el factor salinidad (SM0 y CM0), se pueden observar diferencias significativas entre plántulas con y sin micorrizas, donde plántulas que recibieron el inóculo de G. proliferum presentaron mayor absorción de nutrientes referidos al componente 1 , en especial del $\mathrm{P}$, con lo cual se demuestra el papel de la micorriza, ayudando a que la planta absorba este importante nutriente, resultados que concuerdan con lo reportado por Roveda et al. (2007), Ruiz-Lozano y Azcón (2000). El fósforo es un nutriente importante para las plántulas debido a que participa en la respiración y fotosíntesis, también es un elemento que actúa en el metabolismo de las plántulas en forma de ATP y hace parte de ácidos nucleicos. El uso de micorrizas mejora la absorción de fósforo, e igualmente participa en la toma de nutrientes esenciales como nitrógeno (Roveda et al., 2007).

Respecto al componente 2 (absorción de Ca y $\mathrm{Na}$ ) se puede observar el efecto de las micorrizas mejorando la toma de estos nutrientes bajo condiciones salinas, es de resaltar que, aunque lo ideal es que la planta absorba calcio; la competencia a nivel de carga eléctrica entre estos dos iones se ve desbalanceada en condiciones salinas, favoreciendo la toma de sodio, el cual resulta tóxico para los tejidos. 


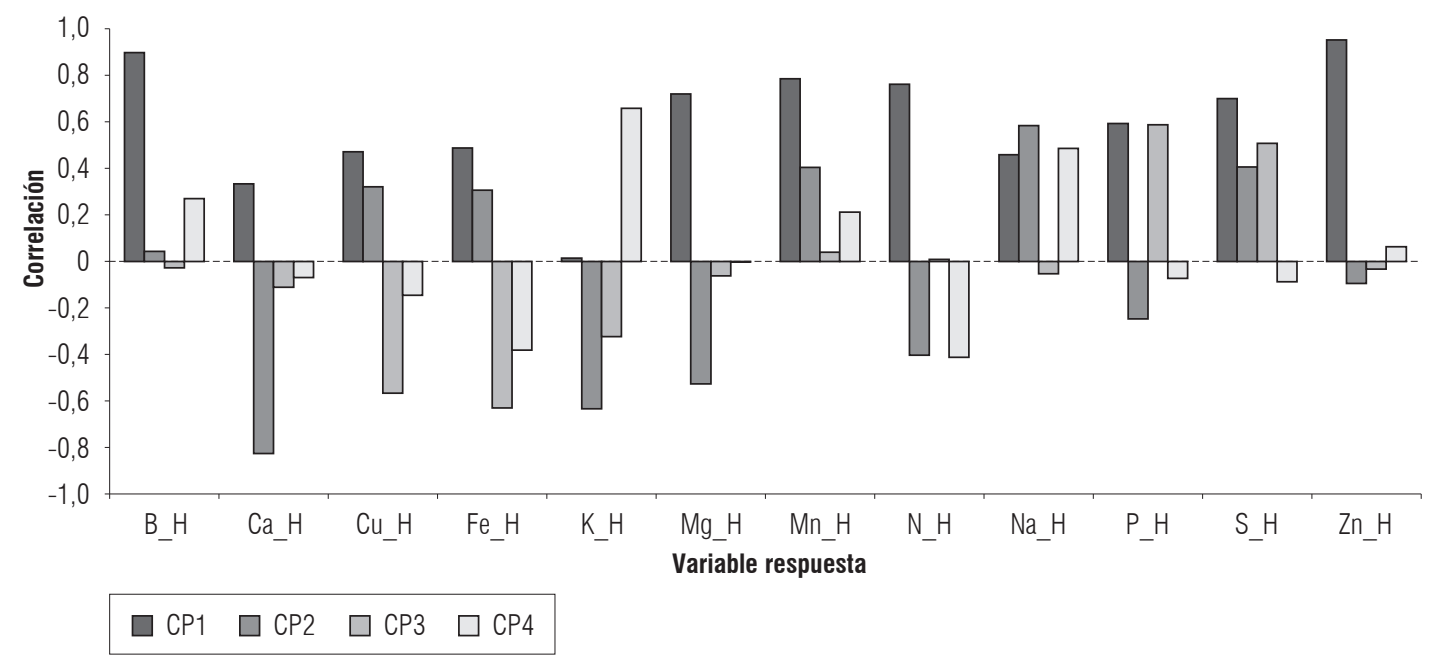

Figura 5. Análisis de componentes principales (ACP) para las variables respuesta correspondientes a la absorción de nutrientes por la hoja (H).

Tabla 3. Prueba de comparación para los componentes CP1, CP2, CP3 y CP4 correspondientes al grupo de variables del conjunto "Absorción de nutrientes en hoja". Promedios con letras distintas indican diferencia significativa según la prueba de Tukey $(P \leq 0,05) . n=3$.

\begin{tabular}{|c|c|c|c|c|c|c|c|}
\hline CP & Tratamientos & Media & $P$ & CP & Tratamientos & Media & $P$ \\
\hline \multirow{8}{*}{ CP1 } & CM40 & 3,551 & $\mathrm{a}$ & \multirow{8}{*}{ CP2 } & CM120 & 3,253 & $\mathrm{a}$ \\
\hline & SM120 & 2,454 & $a b$ & & CM80 & 1,146 & $b$ \\
\hline & CM80 & 0,9377 & $a b c$ & & SM120 & 0,2633 & $\mathrm{bc}$ \\
\hline & SM80 & $-0,49$ & $\mathrm{bcd}$ & & CM40 & $-0,6267$ & $\mathrm{~cd}$ \\
\hline & CMO & $-0,578$ & $\mathrm{~cd}$ & & SM40 & $-0,7367$ & $\mathrm{~cd}$ \\
\hline & CM120 & $-1,412$ & $\mathrm{~cd}$ & & CMO & $-0,7637$ & $\mathrm{~cd}$ \\
\hline & SM40 & $-2,05$ & $d$ & & SM80 & $-1,16$ & $c d$ \\
\hline & SMO & $-2,413$ & $d$ & & SMO & $-1,375$ & $d$ \\
\hline \multirow{8}{*}{ CP3 } & CMO & 1,802 & a & \multirow{8}{*}{$\mathrm{CP} 4$} & SM120 & 1,957 & $\mathrm{a}$ \\
\hline & CM80 & 0,99 & $a b$ & & SM80 & 0,2073 & $b$ \\
\hline & SM120 & 0,6617 & $a b c$ & & SM40 & 0,07033 & $b c$ \\
\hline & SMO & 0,278 & $a b c$ & & CM120 & 0,069 & $b c$ \\
\hline & CM40 & $-0,775$ & $b c$ & & SMO & $-0,0297$ & $b c$ \\
\hline & CM120 & $-0,871$ & $\mathrm{bc}$ & & CMO & $-0,197$ & $b c$ \\
\hline & SM80 & $-1,022$ & c & & CM80 & $-0,5267$ & $b c$ \\
\hline & SM40 & $-1,063$ & c & & CM40 & $-1,55$ & c \\
\hline
\end{tabular}

En el componente tres se puede observar el efecto benéfico que tienen las micorrizas en la absorción de micronutrientes (Fe y $\mathrm{Cu}$ ), en condiciones normales y salinas $(0,40$ y $80 \mathrm{mM})$. Cuando la concentración salina se incrementa a $120 \mathrm{mM}$, el efecto benéfico de la micorriza desaparece y comienza a reducir su nivel en tejido por translocación de nutrientes y fotoasimilados al hongo. Por otro lado, la absorción de potasio en hojas mostró un comportamiento indiferente a la inoculación con micorrizas, ya que no 
se presentaron diferencias estadísticamente significativas entre plántulas con y sin micorrizas, ni bajo diferentes soluciones salinas, lo que demuestra la preferencia de la planta de mora por absorber potasio (Bolaños et al., 2014).

\section{Absorción de nutrientes en tallo}

En la figura 6 se presenta la correlación entre variables asociadas a la absorción de nutrientes en tallos de plántulas de mora y componentes extraídos a partir de estas variables. Cuatro componentes (CP1, CP2, CP3 y CP4) representaron 87,3\% de la variabilidad acumulada de los datos.

Mediante MANOVA se encontró interacción significativa $(P<0.0001)$ entre salinidad y micorrizas (Tab. 4) para la absorción de nutrientes en tallo.

En el componente 1 (absorción de N, K, Mg, S y micronutrientes) se puede observar mayor absorción en plántulas micorrizadas que estuvieron bajo condiciones de altas concentraciones salinas (120 mM) en contraste con plántulas que recibieron la misma concentración, pero cuyo sustrato no fue inoculado. Esto quiere decir que las micorrizas ayudan a una mejor absorción nutricional cuando la planta se encuentra en condiciones de alta salinidad, e incluso sin estrés salino (Tab. 4). Al respecto, Giri y Mukerji (2004) encontraron una mayor acumulación de $\mathrm{N}$ en plantas micorrizadas de Sesbania grandiflora y S. aegyptiaca que en plantas control (no micorrizadas). En contraste, en el componente 2 (absorción de P y Ca) fue significativamente menor en plántulas que fueron micorrizadas, situación que se puede explicar porque al mejorarse la absorción de P por el tallo, este puede unirse con $\mathrm{Ca}$, con la consecuente precipitación como fosfatos de calcio en condiciones salinas o normales (Martínez, 1995). El componente 4 no presentó diferencias significativas.

La absorción de sodio en tallo (componente 3) fue superior en plántulas no micorrizadas en contraste con las que recibieron el inóculo, lo cual concuerda con lo encontrado por Al-Karaki (2006), quien afirma que el mejor crecimiento en plántulas inoculadas con HFMA se debió al aumento de la adquisición de nutrientes minerales con baja movilidad, como P, Zn, $\mathrm{Cu}$ y Fe, y a la toma reducida del $\mathrm{Na}$. Por lo cual es recomendable la inoculación de plántulas de mora con micorrizas, cuando se presenten condiciones de salinidad en el suelo.

\section{Absorción de nutrientes en raíz}

En la figura 7 se presenta la correlación entre variables asociadas a la absorción de nutrientes en raíz de plántulas de mora y componentes extraídos a partir de dichas variables.

Mediante MANOVA se encontró interacción significativa $(P \leq 0.0001)$ entre salinidad y micorrizas (Tab. 5) para la absorción de nutrientes en raíz.

En el componente 1 (absorción de nutrientes, exceptuando P, S y K) se puede observar que plántulas

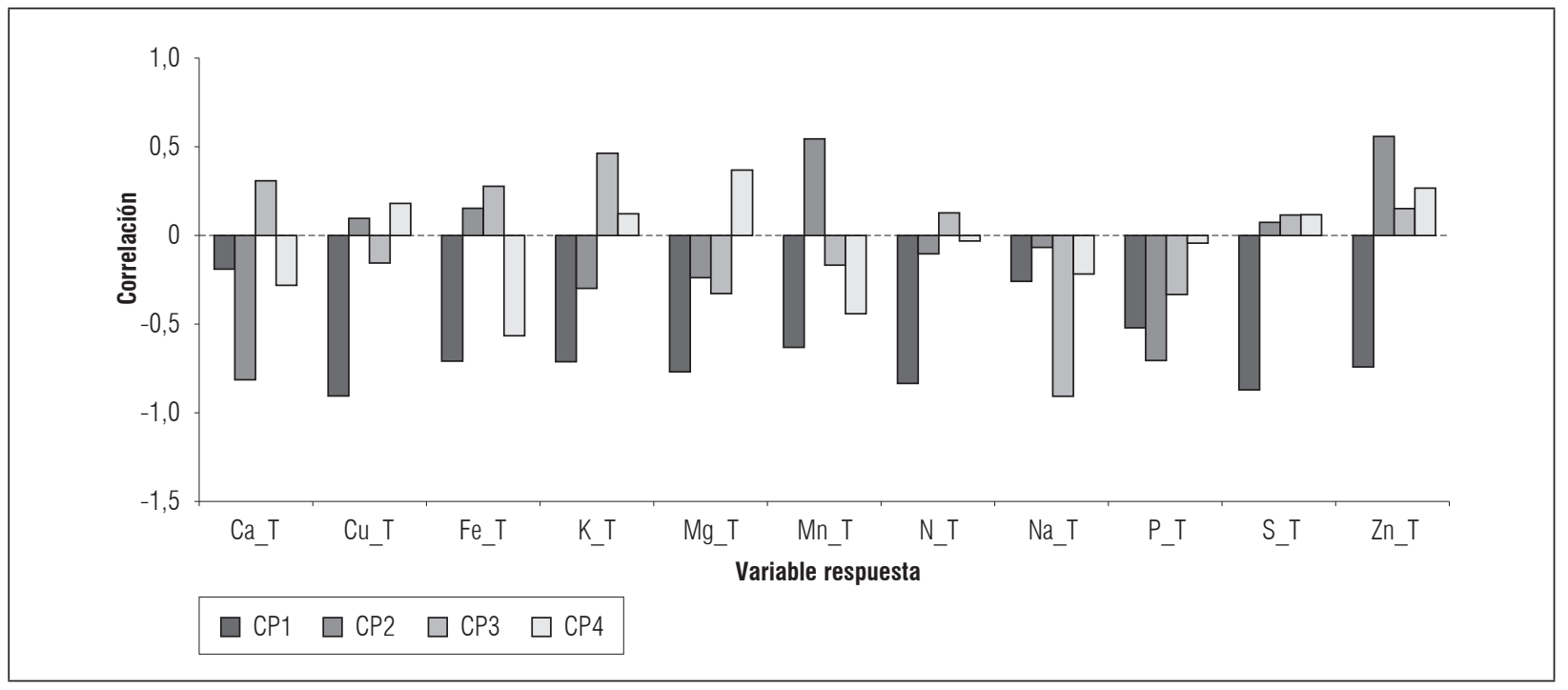

Figura 6. Análisis de componentes principales (ACP) para las variables respuesta correspondientes a la absorción de nutrientes por el tallo (T). 
Tabla 4. Prueba de comparación para los componentes CP1, CP2 y CP3, correspondientes al grupo de variables "Absorción de nutrientes en tallo". Promedios con letras distintas indican diferencia significativa según la prueba de Tukey $(P \leq 0,05)$. $n=3$.

\begin{tabular}{|c|c|c|c|c|c|c|c|}
\hline CP & Tratamientos & Media & $\boldsymbol{P}$ & CP & Tratamientos & Media & $P$ \\
\hline \multirow{8}{*}{ CP1 } & CM120 & 2,063 & a & \multirow{8}{*}{$\mathrm{CP} 2$} & SM80 & 1,845 & a \\
\hline & CMO & 1,91 & $a b$ & & SM0 & 1,186 & $a b$ \\
\hline & SM40 & 1,354 & $a b c$ & & CM120 & 0,6375 & $a b$ \\
\hline & SM80 & 1,108 & $a b c$ & & CM40 & $-0,193$ & $a b$ \\
\hline & CM80 & 0,6942 & $a b c$ & & CM80 & $-0,237$ & $a b$ \\
\hline & SMO & $-1,612$ & bcd & & SM120 & $-0,7362$ & $a b$ \\
\hline & CM40 & $-1,7$ & $\mathrm{~cd}$ & & SM40 & $-1,002$ & $a b$ \\
\hline & SM120 & $-3,817$ & $d$ & & CMO & $-1,505$ & $b$ \\
\hline \multirow{8}{*}{ CP3 } & SMO & 2,2 & a & & & & \\
\hline & CMO & 1,039 & bcd & & & & \\
\hline & SM40 & 0,5893 & bcd & & & & \\
\hline & CM40 & 0,3314 & $\mathrm{~cd}$ & & & & \\
\hline & SM80 & $-0,3949$ & $d$ & & & & \\
\hline & CM80 & $-0,9003$ & de & & & & \\
\hline & SM120 & $-1,378$ & e & & & & \\
\hline & CM120 & $-1,487$ & e & & & & \\
\hline
\end{tabular}

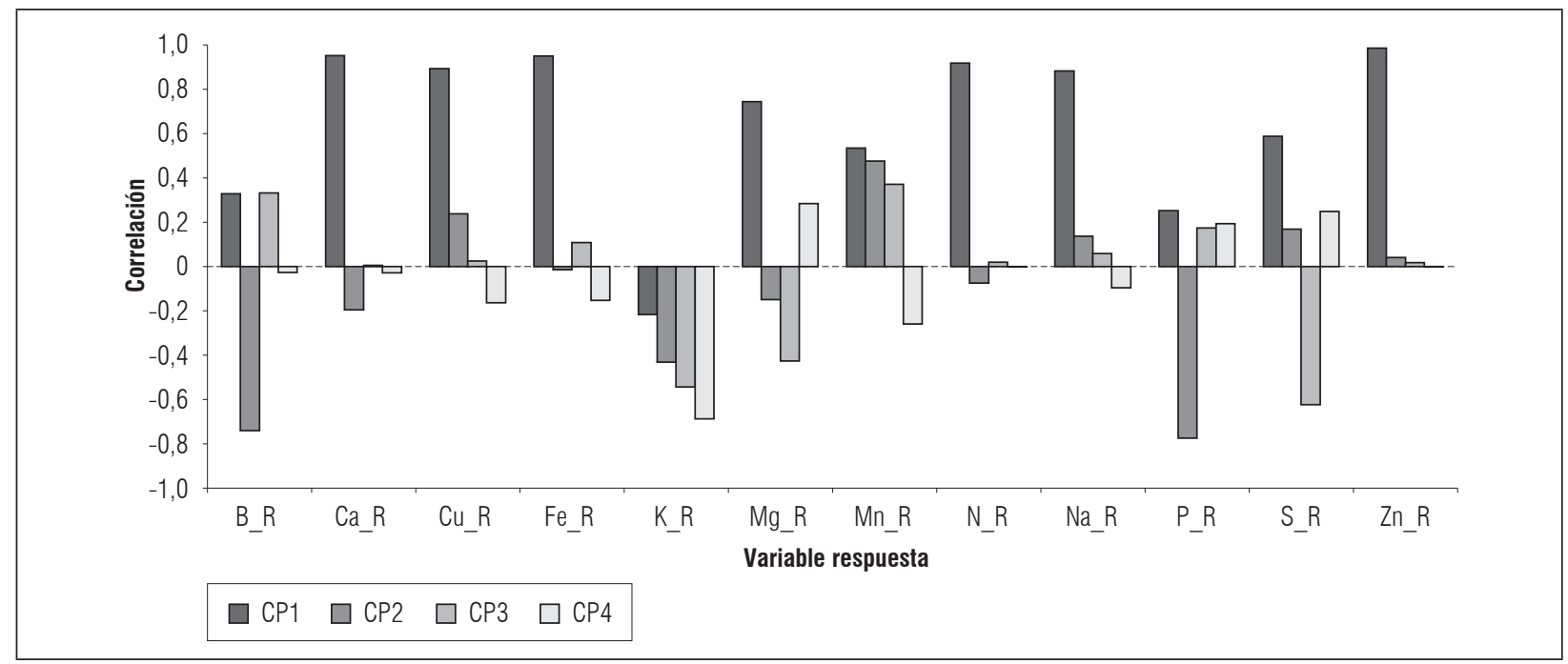

Figura 7. Análisis de componentes principales (ACP) para las variables respuesta correspondientes a la absorción de nutrientes por la raíz (R).

micorrizadas bajo la concentración salina más alta (Tab. 5) presentaron la mejor absorción de estos nutrientes con respecto a plántulas micorrizadas en medios salinos más bajos. Al respecto, una concentración más alta de $\mathrm{Ca}^{2+}$ en plantas de plátano micorrizadas que en las no micorrizadas, fue reportada por Yano-Melo et al. (2003). El Ca ${ }^{2+}$ alto tiene un efecto benéfico sobre los efectos tóxicos del $\mathrm{NaCl}$ al facilitar una mayor selectividad de $\mathrm{K}^{+} / \mathrm{Na}^{+}$que conduce a la adaptación de la sal (Rabie y Almadini, 2005). Además, también se encontró que un alto contenido de $\mathrm{Ca}^{2+}$ potenciaba la colonización y la esporulación de HFMA (Jarstfer et al., 1998). Sin embargo, Giri et al. (2003) encontraron que la concentración de $\mathrm{Ca}^{2+}$ 
Tabla 5. Prueba de comparación de para los componentes CP1, CP2 y CP3, correspondientes al grupo de variables "Absorción de nutrientes en raíz". Promedios con letras distintas indican diferencia significativa según la prueba de Tukey $(P \leq 0,05) . n=3$.

\begin{tabular}{|c|c|c|c|c|c|c|c|}
\hline CP & Tratamientos & Media & $P$ & CP & Tratamientos & Media & $P$ \\
\hline \multirow{8}{*}{ CP1 } & SM120 & 4,90 & $\mathrm{a}$ & \multirow{8}{*}{ CP2 } & CM80 & 1,57 & $\mathrm{a}$ \\
\hline & CM120 & 1,14 & $a b$ & & $\mathrm{CM} 40$ & 0,66 & $\mathrm{a}$ \\
\hline & SMO & 0,64 & $\mathrm{~b}$ & & SM120 & 0,57 & $\mathrm{a}$ \\
\hline & CM40 & $-0,42$ & $b$ & & $\mathrm{CMO}$ & 0,46 & $\mathrm{a}$ \\
\hline & CM80 & $-0,57$ & $b$ & & SM40 & $-0,11$ & $\mathrm{a}$ \\
\hline & CMO & $-0,78$ & $b$ & & SM80 & $-0,30$ & $a$ \\
\hline & SM40 & $-2,38$ & $\mathrm{~b}$ & & CM120 & $-0,32$ & $\mathrm{a}$ \\
\hline & SM80 & $-2,54$ & $b$ & & SMO & $-2,53$ & $\mathrm{~b}$ \\
\hline \multirow{8}{*}{ CP3 } & CM80 & 1,30 & $a$ & \multirow{8}{*}{$\mathrm{CP} 4$} & CMO & 1,01 & $\mathrm{a}$ \\
\hline & CM120 & 0,87 & $a b$ & & CM120 & 0,65 & $\mathrm{a}$ \\
\hline & SM0 & 0,46 & $a b c$ & & CM40 & 0,49 & $\mathrm{a}$ \\
\hline & SM40 & 0,35 & $a b c$ & & SM40 & 0,11 & $a b$ \\
\hline & SM120 & 0,01 & $a b c$ & & SM0 & $-0,02$ & $a b$ \\
\hline & SM80 & $-0,37$ & $\mathrm{bc}$ & & CM80 & $-0,33$ & $a b$ \\
\hline & $\mathrm{CMO}$ & $-0,53$ & C & & SM120 & $-0,56$ & $a b$ \\
\hline & CM40 & $-2,09$ & $d$ & & SM80 & $-1,34$ & $\mathrm{~b}$ \\
\hline
\end{tabular}

permanece inalterada en los tejidos de plantas micorrizadas y no micorrizadas de Acacia auriculiformis. A pesar de lo anterior, no se observan diferencias significativas entre plántulas que fueron inoculadas y no inoculadas. Aunque no se presentaron diferencias significativas para variables asociadas al componte 2 (absorción de P y B), se puede evidenciar que en condiciones normales (no salinas), plántulas micorrizadas promueven la absorción de P y B; resultados que afirman el papel de las micorrizas en mejorar la toma de nutrientes, principalmente fósforo (Roveda et al., 2007).

Respecto a la absorción de azufre (componente 3), plántulas de mora micorrizadas (sin solución salina) y que recibieron una solución salina de $40 \mathrm{mM}$ presentaron mayor absorción de este nutriente, y fueron estadísticamente diferentes de plántulas sin micorrizar que recibieron la misma concentración salina. Sin embargo, plántulas que recibieron concentraciones más altas de $\mathrm{NaCl}$, y cuyo sustrato fue inoculado, presentaron menor absorción de este nutriente; ya que probablemente por encima de una concentración 80 $\mathrm{mM} \mathrm{NaCl}$, la micorrización se ve afectada.

La micorriza permitió mayor selectividad de potasio que por sodio, de igual carga. Es decir, que en condiciones salinas y aún en condiciones normales, la aplicación de micorrizas al momento del trasplante genera una adecuada absorción de potasio.

\section{CONCLUSIONES}

El uso de micorrizas puede ayudar a las plántulas de mora a tolerar concentraciones medias de salinidad en el suelo (40 mM de $\mathrm{NaCl}$ ); al permitir una mayor absorción de nutrientes como fósforo y una menor toma de sodio.

La micorriza promueve el transporte de nutrientes claves en el crecimiento aéreo de la mora, como es el caso del nitrógeno, donde este nutriente permitió una mayor acumulación de materia seca en órganos aéreos.

Las micorrizas permitieron que las plántulas de mora absorbieran potasio en mayor proporción, en vez de absorber sodio (la micorriza permitió una mayor selectividad por este nutriente). Igualmente, la mayor absorción de nutrientes se presentó en plántulas que fueron inoculadas con la cepa de micorrizas.

Es importante resaltar el efecto benéfico de las micorrizas cuando las plántulas de mora se encuentran en un sustrato con concentraciones salinas bajas a medias; sin embargo, cuando la concentración salina es muy alta, la plántula al parecer empieza a traslocar sus fotoasimilados para el sostenimiento del hongo, sacrificando su crecimiento.

Conflicto de intereses: el manuscrito fue preparado y revisado con la participación de los autores, 
quienes declaran no tener algún conflicto de interés que coloquen en riesgo la validez de los resultados aquí presentados.

\section{REFERENCIAS BIBLIOGRÁFICAS}

Al-Karaki, G.N. 2006. Nursery inoculation of tomato with arbuscular mycorrhizal fungi and subsequent performance under irrigation with saline water. Sci. Hortic. 109(1), 1-7. Doi: 10.1016/j.scienta.2006.02.019

Ashraf, M. y A. Bashir. 2003. Salt stress induced changes in some organic metabolites and ionic relations in nodules and other plant parts of two crop legumes differing in salt tolerance. Flora 198(6), 486-498. Doi: 10.1078/0367-2530-00121

Bertsch, F. 2005. Estudios de absorción de nutrientes como apoyo a las recomendaciones de fertilización. Informaciones agronómicas No. 57. INPOFOS, Quito, Ecuador.

Blaha, G., U. Stelzl, C.M.T. Spahn, R.K. Agrawal, J. Frank y K.H. Nierhaus. 2000. Preparation of functional ribosomal complexes and effect of buffer conditions on tRNA positions observed by cryoelectron microscopy. Methods Enzymol. 317, 292-309. Doi: 10.1016/ S0076-6879(00)17021-1

Bolaños, M.M., W.A. Cardona, W.L. Ramírez y J.H. Argue1les. 2014. Requerimientos nutricionales (N, P, K y Ca) de Rubus glaucus B., durante crecimiento vegetativo. Memorias XX Congreso Latinoamericano y XVI Congreso Peruano de la Ciencia del Suelo. Cuzco, Perú.

Cardona, W.A., L.G. Bautista Montealegre, N. Flórez Velasco y G. Fischer. 2016a. Desarrollo de la biomasa y raíz en plantas de lulo (Solanum quitoense var. septentrionale) en respuesta al sombrío y anegamiento. Rev. Colomb. Cienc. Hortíc. 10(1), 53-65. Doi: 10.17584/ rcch.2016v10i1.5124

Cardona, W.A., O.I. Monsalve, J.S. Gutiérrez y M.M. Bolaños. 2016b. Efecto de N, P, K y Ca sobre crecimiento de mora con tunas en vivero. Memorias XVIII Congreso Colombiano de la Ciencia del Suelo. Villa de Leyva, Colombia.

Cardona, W.A. 2017. Requerimientos nutricionales (nitrógeno, fósforo, potasio y calcio) en etapa vegetativa y reproductiva de un cultivo de mora (Rubus glaucus Benth.), ubicado en el municipio de Silvania (Cundinamarca). Tesis de maestría. Facultad de Ciencias Agrarias, Universidad Nacional de Colombia, Bogotá, Colombia.

Casierra-Posada, F. y H.L. Hernández. 2006. Evapotranspiración y distribución de materia seca en plantas de mora (Rubus sp.) bajo estrés salino. Rev. Act. Divulg. Cient. UDCA 9(1), 85-95.

Casierra-Posada, F., G. Ebert y P. Lüdders. 2000. Efecto de la salinidad por cloruro de sodio sobre el balance de nutrientes en plantas de lulo (Solanum quitoense L.). Agron. Colomb. 17, 85-90.

Chinnusamy, V., A. Jagendore y Z. Jian-Kang. 2005. Understanding and improving salt tolerance in plants. Crop Sci. 45(2), 437-448. Doi: 10.2135/cropsci2005.0437

Colla, G., Y. Rouphael, M. Cardarelli, M. Tullio, C.M. Rivera y E. Rea. 2008. Alleviation of salt stress by arbuscular mycorrhizal in zucchini plants grown at low and high phosphorus concentration. Biol. Fert. Soils. 44(3), 501-509. Doi: 10.1007/s00374-007-0232-8

De Mendiburu, F. 2015. Agricolae: Statistical procedures for agricultural research. R package version 1.2-2. En: http://CRAN.R-project.org/package=agricolae, consulta: febrero de 2017.

Dodd, I.C. y W.J. Davies. 2004. Hormones and the regulation of water balance. En: Davies, P.J. (ed.). Plant hormones: Biosynthesis, signal transduction, action. Kluwer Academic Publ., Dordrecht, The Netherlands.

El-Desouky, S.A. and A.A.R. Atawia. 1998. Growth perfomance of citrus rootstocks under saline conditions. Alexandria J. Agric. Res. 43, 231-254.

Ghoulam, C., A. Foursy y K. Fares. 2002. Effects of salt stress on growth inorganic ions and proline accumulation in relation to osmotic adjustment in five sugar beet cultivars. Environ. Exp. Bot. 47(1), 39-50. Doi: 10.1016/S0098-8472(01)00109-5

Giri, B., R. Kapoor y K.G. Mukerji. 2003. Influence of arbuscular mycorrhizal fungi and salinity on growth, biomass and mineral nutrition of Acacia auriculiformis. Biol. Fert. Soils 38(3), 170-175. Doi: 10.1007/ s00374-003-0636-z

Giri, B. y K.G. Mukerji. 2004. Mycorrhizal inoculant alleviates salt stress in Sesbania aegyptiaca and Sesbania grandiflora under field conditions: evidence for reduced sodium and improved magnesium uptake. Mycorrhiza 14(5), 307-312. Doi: 10.1007/s00572-003-0274-1

Giri, B., R. Kapoor y K.G. Mukerji. 2007. Improved tolerance of Acacia nilotica to salt stress by arbuscular mycorrhiza, Glomus fasciculatum, may be partly related to elevated $\mathrm{K}^{+} / \mathrm{Na}^{+}$ratios in root and shoot tissues. Microbial Ecol. 54(4), 753-760. Doi: 10.1007/ s00248-007-9239-9

Goykovic, V. y G. Saavedra. 2007. Algunos efectos de la salinidad en el cultivo del tomate y prácticas agronómicas de su manejo. Idesia 25(3), 47-58. Doi: 10.4067/ S0718-34292007000300006

Grattan, S.R. y C.M. Grieve. 1999. Salinity mineral nutrient relations in horticultural crops. Sci. Hortic. 78 (1-4), 127-157. Doi: 10.1016/S0304-4238(98)00192-7

Jarstfer, A.G., P. Farmer-Koppenol y D.M. Sylvia. 1998. Tissue magnesium and calcium affect mycorrhiza development and fungal reproduction. Mycorrhiza 7(5), 237-242. Doi: 10.1007/s005720050186

Kepenek, K. y F. Koyuncu. 2002. Effect of salt expression of resistance in some domestic foreign strawberry 
cultivars. Acta Hortic. 573, 289-295. Doi: 10.17660/ ActaHortic.2002.573.33

Marschner, H. 2002. Mineral nutrition of higher plants. Academic Press, Amsterdam, The Netherlands.

Martínez, G.F. 1995. Elementos de la fisiología vegetal. Ediciones Mundi Prensa, Madrid, España.

Memon, S.A., X. Hou y L.J. Wang. 2010. Morphological analysis of salt stress response of pak Choi. Electron. J. Environ. Agric. Food Chem. 9(1), 248-254.

Miranda, D. 2011. Effect of salt stress on physiological parameters of cape gooseberry, Physalis peruviana L. Tesis de doctorado. Humboldt-Universität zu Berlin, Alemania.

Miranda, D., C. Ulrichs y G. Fischer. 2012. Efecto del cloruro de sodio $(\mathrm{NaCl})$ sobre el crecimiento y colonización micorrízica en uchuva (Physalis peruviana L.). pp. 15-25. Avances de la investigación agronómica II. Facultad de Agronomía, Universidad Nacional de Colombia, Bogotá, Colombia.

Mohamedin, A., A. El-Kader y N. Badran, 2006. Response of sunflower (Helianthus annuus L.) to plants salt stress under different water table depths. J. Appl. Sci. Res. 2(12), 1175- 1184.

Munns, R. 2002. Comparative physiology of salt and water stress. Plant Cell Environ. 25, 239-250. Doi: 10.1046/j.0016-8025.2001.00808.x

Munns, R., S. Goyal y J. Passioura. 2005. Salinity and its mitigation. University of California, Davis, CA, USA.

Murkute, A.A., S. Sharma y S.K. Singh. 2006. Studies on salt stress tolerance of citrus rootstock genotypes with arbuscular mycorrhizal fungi. HortScience 33, 70-76.

NTC-ISO/IEC 17025. 2005. Requisitos generales para la competencia de los laboratorios de ensayo y de calibración. En: https://www.iso.org/obp/ui/\#iso:std:iso-iec:17025:ed-2:v1:es; consulta: marzo de 2017.

Pérez, A. y V. Peroza. 2013. Micorrizas arbusculares asociadas al pasto angleton (Dichathium aristatum Benth) en fincas ganaderas del municipio de Tolú, Sucre-Colombia. Rev. MVZ 18(1), 3362-3369. Doi: 10.21897/ rmvz.199

Rabie, G.H y A.M. Almadini. 2005. Role of bioinoculants in development of salt-tolerance of Vicia faba plants under salinity stress. Afr. J. Biotechnol. 4, 210-222.

Rilling, M.C. y D.L. Mummey. 2006. Mycorrhizas and soil structure. New Phytologist 171, 41-53. Doi: 10.1111/j.1469-8137.2006.01750.x

Roveda, G., L. Cabra, M. M. Ramírez y A. Peñaranda. 2007. Efecto de las micorrizas arbusculares sobre la aclimatación y endurecimiento de microplántulas de mora (Rubus glaucus). Corpoica Ciencia Tecnol. Agropec. 8(1), 28-36. Doi: 10.21930/rcta.vol8_num1_art:80

Rui, L., S. Wei, C. Mu-xiang, J. Cheng-jun, W. Min e Y. Bo-ping. 2009. Leaf anatomical changes of Burguiera gymnorhiza seedlings under salt stress. J. Trop. Subtrop. Bot. 17(2), 169-175.

Ruiz-Lozano, J.M. y R. Azcón. 2000. Symbiotic efficiency and infectivity of an autochthonous arbuscular mycorrhizal Glomus sp from saline soils and Glomus deserticola under salinity. Mycorrhiza 10(3), 137-143. Doi: 10.1007/s005720000075

Saint-Etienne, L., S. Paul, D. Imbert, M. Dulormne, F. Muller, A. Toribio, C. Plenchette y A.M. Bâ. 2006. Arbuscular mycorrhizal soil infectivity in a stand of the wetland tree Pterocarpus officinalis along a salinity gradient. For. Ecol. Manag. 232(1-3), 86-89. Doi: 10.1016/j.foreco.2006.05.046

Sharifi, M., M. Ghorbanli y H. Ebrahimzadeh. 2007. Improved growth of salinity-stressed soybean after inoculation with pre-treated mycorrhizal fungi. J. Plant Physiol. 164(9), 1144-1151. Doi: 10.1016/j. jplph.2006.06.016

Sheng, M., M. Tang, H. Chan, B. Yang, F. Zhang y Y. Huang. 2008. Influence of arbuscular mycorrhizae on photosynthesis and water status of maize plants under salt stress. Mycorrhiza 18 (6-7), 287-296. Doi: 10.1007/s00572-008-0180-7

Shokri, S. y B. Maadi. 2009. Effects of arbuscular mycorrhizal fungus on the mineral nutrition and yield of Trifolium alexandrium plants under salinity stress. J. Agron. 8, 79-83. Doi: 10.3923/ja.2009.79.83

Smith, E. y D.J. Read. 2008. Mycorrhizal symbiosis. Academic Press, London, UK.

Ulloa, L.N., N.A. Vargas, D. Miranda y G. Fischer. 2006. Efecto de la salinidad sobre los parametros de desarrollo en especies horticolas cultivadas en sistemas sin suelo. pp. 53-76. En: Florez, V.J., A. de la C. Fernandez, D. Miranda, B. Chaves y J.M. Guzman (eds.). Avances sobre fertirriego en la floricultura colombiana. Unibiblos, Universidad Nacional de Colombia, Bogotá, Colombia.

Valenzuela, J.L., M. Guzmán, A. Sánchez, A. del Río y L. Romero. 1993. Relationship between biochemical indicators and physiological parameters of nitrogen and physiological plant age. En: Fragoso, M. y M. van Beusichem (eds.). Optimization of plant nutrition. Kluwer Academic Publ., Dordrecht, The Netherlands. Doi: 10.1007/978-94-017-2496-8_40

Yano-Melo, A.M., O.J. Saggin y L.C. Maia. 2003. Tolerance of mycorrhized banana (Musa sp. cv. Pacovan) plantlets to saline stress. Agric. Ecosyst. Environ. 95(1), 343-348. Doi: 10.1016/S0167-8809(02)00044-0

Zuccarini, P. 2007. Mycorrhizal infection ameliorates chlorophyll content and nutrient uptake of lettuce exposed to saline irrigation. Plant Soil Environ. 53, 283-289.

Zuccarini, P. y P. Okurowska. 2008. Effects of mycorrhizal colonization and fertilization on growth and photosynthesis of sweet basil under salt stress. J. Plant Nutr. 31, 497-513. Doi: 10.1080/01904160801895027 